http://jmscr.igmpublication.org/home/ ISSN (e)-2347-176x ISSN (p) 2455-0450 crossref DOI: https://dx.doi.org/10.18535/jmscr/v9i6.27

\title{
Stromal Expression of CD 10 in Infiltrating Duct Carcinoma Breast and Its Correlation with ER, PR, and HER 2 NEU
}

\author{
Authors \\ Dr Ishant Sharma ${ }^{1}$, Dr Sudarshan K Sharma ${ }^{2}$, Dr Anchana Gulati ${ }^{3}$, \\ Dr Anjali Mahajan ${ }^{4}$, Dr Upender Chandel ${ }^{5}$ \\ ${ }^{1}$ JR, III Year, Deptt of Pathology, IGMC, Shimla \\ ${ }^{2}$ Prof \& Head, Deptt of Pathology, IGMC, Shimla \\ ${ }^{3}$ Associate Professor, Deptt of Pathology, IGMC, Shimla \\ ${ }^{4}$ Associate Professor, Deptt of Community Medicine, IGMC, Shimla \\ ${ }^{5}$ Professor, Deptt of Surgery, IGMC, Shimla
}

\begin{abstract}
Background: Breast carcinoma is an epithelial malignancy and it is hormone dependent mostly. Breast carcinoma is the most frequently diagnosed malignancy among the women of all ages worldwide. In 2012, breast carcinoma was found to be the most common malignancy amongst women in India, way ahead of cervical cancer ${ }^{1,2}$. In the year 2020 the diagnosed cases of breast carcinoma among women were 22,61,419 3. Recently it has been documented that tumor progression is promoted by interaction of tumor cells with their microenvironment especially stromal cells. This understanding has brought forth new potential candidate markers like CD10. The aim of this study is to understand the Association of Stromal CD10 expression with ER, PR, HER-2/NEU, in IDC breast.

Methods: Fifty one cases of IDC, breast received as a specimen of modified radical mastectomy in Deptt of Pathology. IHC was done for ER, PR, Her-2/neu and CDIO.

Results: Out of fifty one cases of IDC, stromal CD 10 positivity was seen in $84.3 \%$ of cases .ER and PR positivity was seen in $60.8 \%$ and $54.9 \%$ respectively. However HER-2/neu overexpression was observed only in $21.4 \%$ cases.

Conclusions: In majority of the cases of IDC, the tumor cells were positive for ER and PR. Her-2/neu was positive (score 3+) in only $21.6 \%$ of cases of IDC. Although majority (84.3\%) of the cases of IDC showed stromal CD10 positivity, no statistical significant correlation was observed between stromal CD 10 expression and other IHC markers i.e ER, PR and HER-2/NEU in the cases of IDC breast in our study.
\end{abstract}

\section{Introduction}

Breast carcinoma is a major health problem worldwide as well as in India. It is the most common cancer among women accounting for $18 \%$ of malignancies in females ${ }^{4}$. Many variables have been shown to correlate with prognosis of patients.
IHC has become an important determinant of prognosis and theranostics. Estrogen receptor (ER) is the most important prognostic and predictive marker for breast cancer. Similarly, analysis of Progesterone receptor (PR) expression is generally reported along with ER expression. Most studies have reported that expression of 
estrogen and progesterone receptors indicates favorable response to hormonal therapy and good prognosis ${ }^{5}$. Another receptor is Human epidermal growth factor receptor 2 (HER-2/neu) which is an independent prognostic marker of clinical outcome in patients with metastasis deposits of IDC in lymph nodes ${ }^{6}$. Hence, new markers are being evaluated to understand their role in cancer progression.

Stromal contribution to cancer progression is important as it is related to the tumor invasion and also indicates about metastatic potential of tumors $^{7}$. Stroma also contributes in carcinoma progression as it may promote tumor cell growth, de - differentiation, invasion and ectopic survival of tumor cells ${ }^{8}$. This is why the novel stromal markers are now being studied as potential prognostic markers in invasive breast cancer 9 . Amongst these markers one of the stromal marker is CD10, also known as Neprilysin or Common Acute Lymphoblastic/Lymphoma Antigen (CALLA). It is a 90 to $110-\mathrm{kDa}$ cell surface zinc dependent metalloproteinase ${ }^{8,10}$. Commonly CD10 is expressed in myoepithelial cells of the human breast, lymphoid stem cells, pro-B lymphoblast, mature neutrophils ${ }^{11}$. It is also expressed abnormally in stroma of invasive breast carcinoma, in various subtypes of lymphomas, renal cell carcinoma and endometrial stromal sarcoma $^{11}$. Expression of CD10 in the stroma of invasive breast carcinoma is associated with biological aggressiveness of tumor, higher tumor grade and decreased patient survival. Routine chemotherapeutic drugs target the epithelial cells while stromal cells are spared which could be responsible for recurrences. Therefore CD10 may prove to be a potential target for the development of novel therapies.

This study was conducted to evaluate the correlation between

Stromal CD 10 expression and other IHC marker (ER , PR , Her2/neu) in patients of Infiltrating duct carcinoma of breast.

\section{Material and Methods}

The present study was conducted in the Department of Pathology and Department of Surgery, Indira Gandhi Medical College, Shimla.

Specimens (Modified Radical Mastectomy) received were all the biopsy proven cases of Infiltrating ductal carcinoma of breast w. e. f May 01,2018 to April 30,2020.

Following observations were made:

1. ER,PR,HER-2/NEU status

2. CD10 stromal status

This study comprised of total 51 cases of IDC, breast. Benign lesions breast, carcinoma breast other than IDC and Post neo-adjuvant chemotherapy specimens were not included.

The specimens were fixed in $10 \%$ neutral buffer formalin for not less than 6 hours and not more than 72 hours $^{12}$. Gross findings of the specimen were recorded.

Tissue sections were processed in the fully automated tissue processor of Leica model $6025^{\mathrm{TM}}$.

\section{Immunohistochemical Staining}

Staining was done as per the staining protocol in fully automated IHC BioGenex ${ }^{\text {TM }}$ Xmatrix autoimmunostainer using the mouse monoclonal antibody against CD10.

IHC for ER, PR, Her2-neu were done as per the staining protocol in fully automated Biogenex ${ }^{\mathrm{TM}}$ using monoclonal rabbit antibody.

\section{Controls}

CD10 expression in myoepithelial cells of accompanying normal breast tissue was used as the positive control ${ }^{13,14,15}$.

Known cases of IDC positive for ER, PR and HER-2/neu (score 3+) were used as external controls for the corresponding test IHC markers. Benign breast tissue in the mastectomy specimen accompanying the IDC were also used as internal controls for specificity of immunoreactions for ER and PR 
Results of CD10 stromal staining were correlated with:

$\begin{array}{ll}\text { - } & \text { ER status } \\ \text { - } & \text { PR status } \\ & \text { HER-2/NEU overexpression }\end{array}$

\section{Results}

Allred scoring (Table no. 1) was used to evaluate Estrogen Receptor and Progesterone Receptor status. In our study, 31/51 (60.8\%) cases were ER positive, and 20/51(39.2\%) were ER negative. PR status showed 28/51(54.9\%) cases were PR positive, and 23/51 (45.1\%) were PR negative. ER -, PR + were observed in $4 / 51(7.8 \%)$ cases of IDC.

Out of 51cases of IDC, 11(21.6\%) cases were Her-2/neu positive with a score of $3+$ and 40 (78.43\%) cases were negative for Her2-neu. (assessed as per table no 2).

CD 10 stromal positivity was assessed as described in table no 3.

Benign glands with myoepithelial cells were taken as internal control (Figure 1). CD 10 stromal positivity was observed in 43/51(84.3\%) However strong positivity (Figure 2) for CD10 was observed in 28 cases comprising $55 \%$ of total cases followed by weak positivity (Figure 3 ) in $15 / 51(29.4 \%)$ cases of IDC.

\section{Expression of Stromal CD10 in Infiltrating} Duct Carcinoma breast and its Correlation with ER, PR, HER-2/Neu (Table no. 4)

Majority of ER positive cases, 26/31 (83.9\%) showed positivity for CD10.

Out of all ER negative cases, a higher percentage of cases 17 (85\%) showed positivity for CD10
Majority of PR positive cases 24/28 (85.7\%) showed positivity for CD10.

Out of all PR negative cases a higher percentage of cases 19 (82.6\%) showed positivity for CD10 Majority of HER2-NEU positive cases 10/11 (90.9\%) showed positivity for CD10.

Majority of HER2-NEU negative cases 33/40 $(82.5 \%)$ showed positivity for CD10

CD10 was found to have no correlation with ER , $\mathrm{PR}$ and Her-2/neu in our study. P values were also not statistically significant.

\section{Interpretation of IHC}

\section{Table no. 1}

The results were observed and interpreted as follows:

\section{For ER and PR}

Allred scoring was done

Nuclear staining was taken as positive

Allred Score: Total score 8

\begin{tabular}{|l|c|}
\hline Staining Pattern & Proportion score 0-5 \\
\hline No cell stained & 0 \\
\hline $1 / 100$ cell stained & 1 \\
\hline $1 / 10$ cells stained & 2 \\
\hline $1 / 5$ cells stained & 3 \\
\hline $2 / 3$ cells stained & 4 \\
\hline All cells stained & 5 \\
\hline
\end{tabular}

\begin{tabular}{|c|c|}
\hline Staining Pattern & Intensity Score \\
\hline No staining & 0 \\
\hline Weak staining & 1 \\
\hline Moderate staining & 2 \\
\hline Strong staining & 3 \\
\hline
\end{tabular}

Total score $=$ Proportion score + Intensity score . Total Score of more than 3 or more than 3 was taken as positive.

\section{Table no. 2}

\section{For HER-2/neu:}

Membranous staining was taken as positive and the following grading scheme was followed:

\begin{tabular}{|l|c|c|}
\hline Staining Pattern & Score & Her-2/neu overexpression \\
\hline No staining & 0 & Negative \\
\hline Weak or incomplete membrane staining in any population of cells. & 1 & Negative \\
\hline Complete membrane staining in $<10 \%$ cells. & 2 & Negative \\
\hline Uniform intense membrane staining in $>10 \%$ cells & $3+$ & Positive \\
\hline
\end{tabular}

For the present study, a score of $3+$ was considered as positive immunostaining for HER-2/neu. 


\section{JMSCR Vol||09||Issue||06||Page 137-143||June}

Table no. 3

CD 10 Scoring

Membranous staining was taken as positive and the following grading scheme was followed:

\begin{tabular}{|l|l|}
\hline CD 10 Staining Pattern & Score \\
\hline$<10 \%$ stromal positive cells & Negative \\
\hline $10-30 \%$ stromal positive cells & Weak positive \\
\hline$>30 \%$ stromal positive cells & Strong positive \\
\hline
\end{tabular}

Table no 4 shows the correlation of IHC markers.

Table 4: Correlation of IHC Markers

\begin{tabular}{|l|c|c|c|c|}
\hline RECEPTORS & $\begin{array}{c}\text { CD10 } \\
\text { NEGATIVE }\end{array}$ & $\begin{array}{c}\text { CD10 WEAK } \\
\text { POSITIVE }\end{array}$ & $\begin{array}{c}\text { CD10 STRONG } \\
\text { POSITIVE }\end{array}$ & TOTAL \\
\hline ER positive & 5 & 9 & 17 & 31 \\
\hline ER negative & 3 & 6 & 11 & 20 \\
\hline PR positive & 4 & 7 & 17 & 28 \\
\hline PR negative & 4 & 8 & 11 & 23 \\
\hline Her2-neu postivity & 1 & 2 & 8 & 11 \\
\hline Her2-neu negative & 7 & 12 & 21 & 40 \\
\hline
\end{tabular}

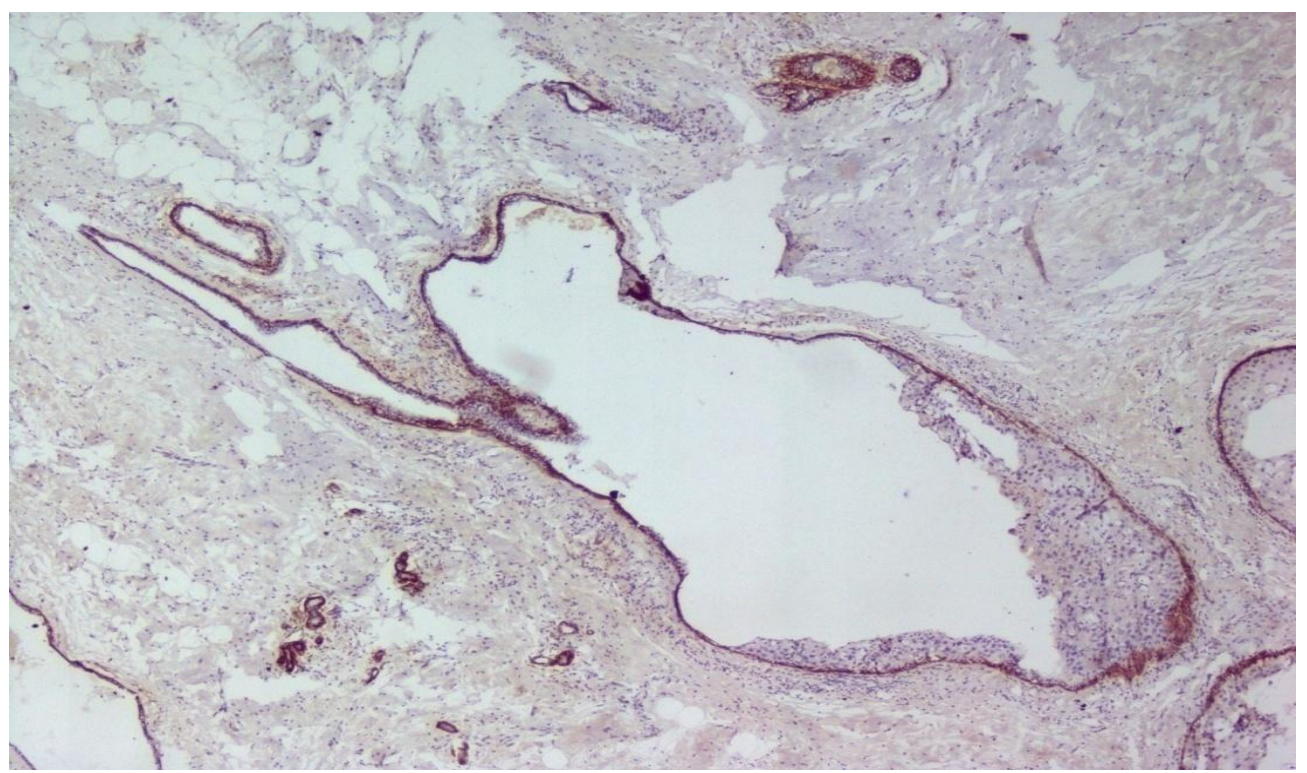

Figure 1: CD 10expression in myoepithelial cells in benign breast glands (x200)

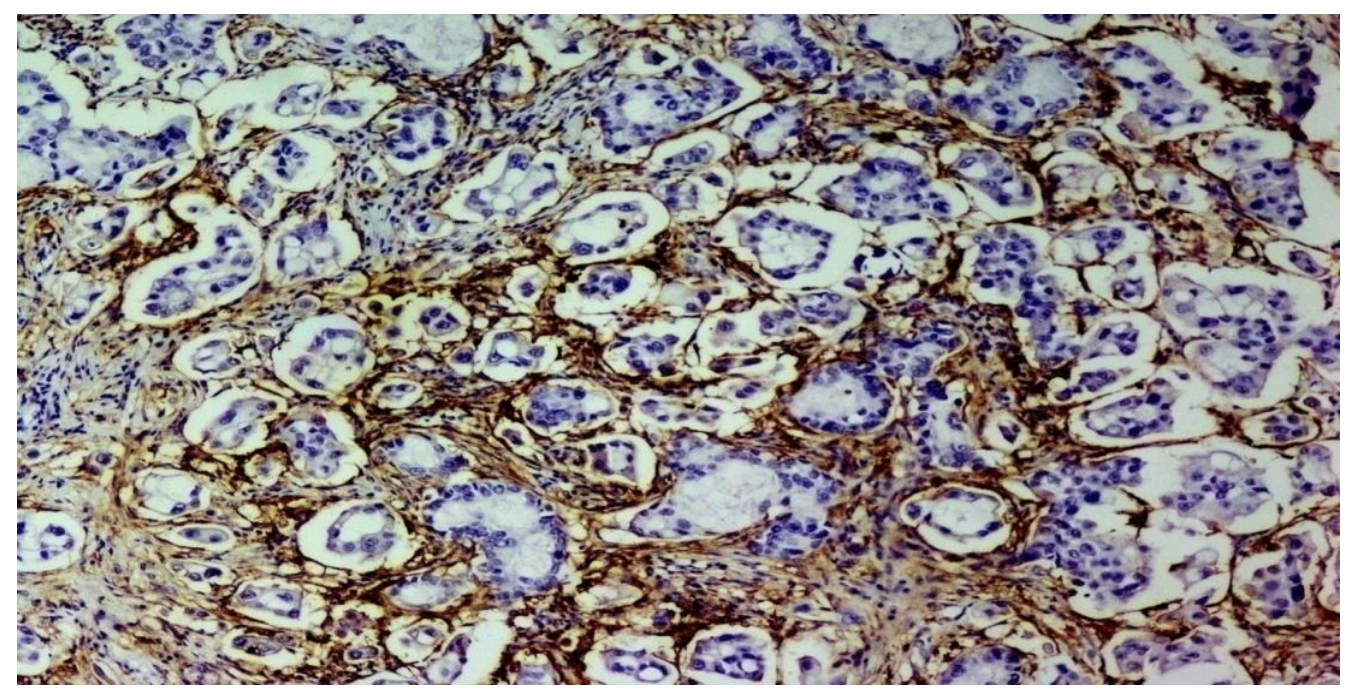

Figure 2: Strong stromal CD 10 positivity in Infiltrating Duct Carcinoma, breast (x200) 


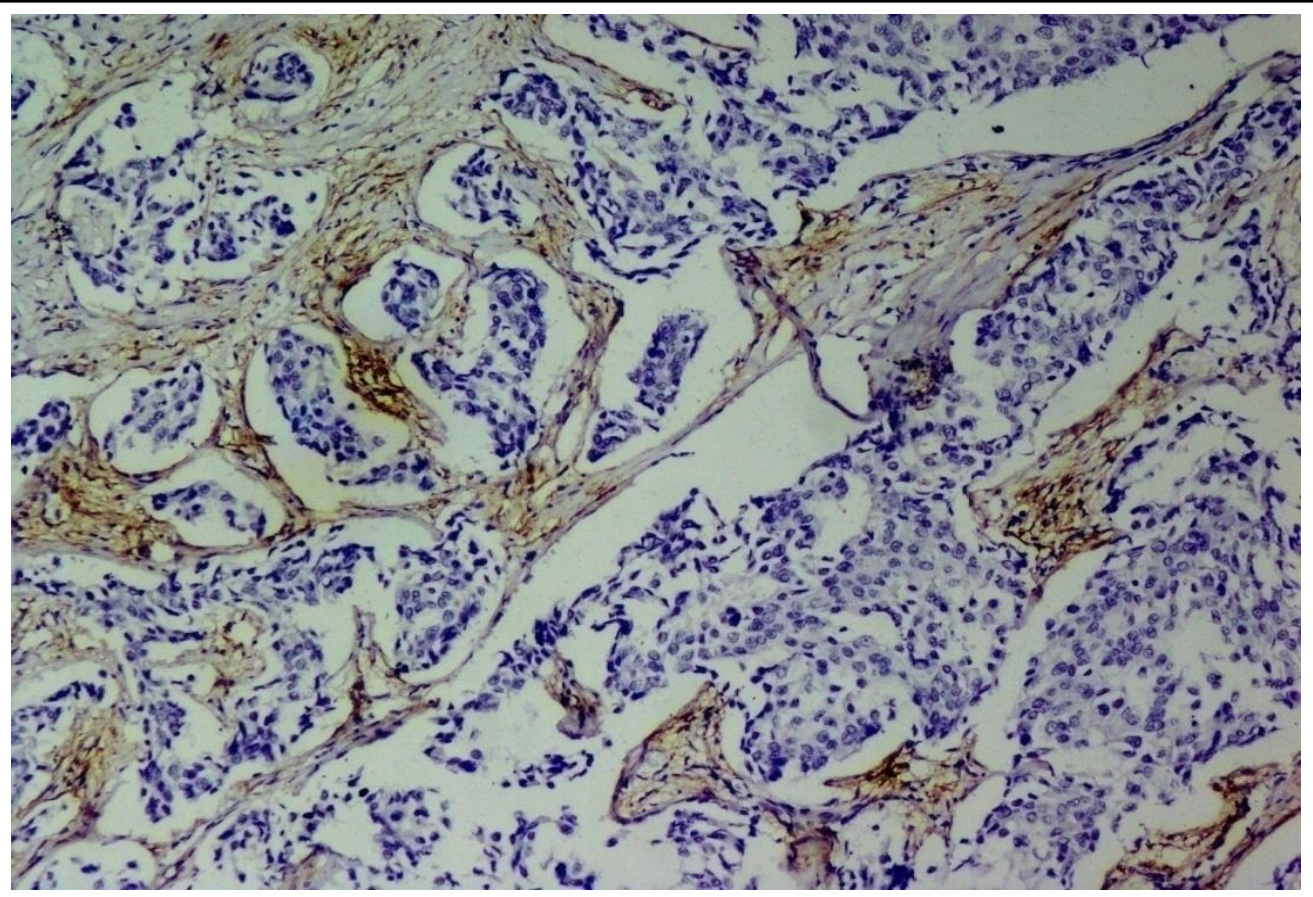

Figure 3: Weak stromal CD 10 positivity in Infiltrating Duct Carcinoma, breast (x200)

\section{Discussion}

CD 10 also known as Common Acute Lymphoblastic Leukemia Antigen (CALLA), is a 90-110 kilo dalton cell surface, membrane bound, zinc dependent matrix metalloproteinase. It is lost in case of IDC with disappearance of myoepithelial cells. ${ }^{16,17}$.

Among various studies in the past it was concluded that CD10 expression by the stromal cells surrounding the breast tumor was correlated with poor prognosis ${ }^{4,16,17}$.

In the present study majority of the cases i. e $84.3 \%$ showed positivity for CD10 which is value intermediate between those observed by Puri V et al and Dhande AN et al. However a study done in 2017 by Azza et al observed strong positivity only in $16.7 \%$ of cases.

In ER positive cases in IDC, CD10 positivity varies widely. However only in studies by Taghizadeh $\mathrm{K}$ et al ${ }^{16}$ and Azza $\mathrm{M}$ et al ${ }^{4}$ there was positive correlation between CD 10 expression and ER positivity ${ }^{16,17}$. In our study we also found $83.8 \%$ of ER positive cases of IDC to be CD 10 positive. But this correlation has not been statistically significant. Puri $\mathrm{V}^{18}$ et al and Mohammadizadeh $\mathrm{F}^{19}$ et al had also observed no statically significant correlation between ER positivity and CD 10 expression.

Similarly we found CD10 positivity in $85.2 \%$ of PR positive cases of IDC but no statistically significant correlation was found between PR positivity and CD 10 expression with a $p$ value of 0.7. This is in accordance with the study by Mohammadizadeh F et al.

A strong correlation between CD10 stromal positivity and Her-2/neu status was observed in the study by Puri V et al. A statistical significant correlation had been found only with a $\mathrm{p}$ value of 0.000 . In comparison to that our study, had showed CD10 positivity in $91 \%$ of Her-2/neu positive cases. But statistically the correlation was not found to be significant similar to other studies in the literature ${ }^{19}$.

We failed to establish any statistical significant correlation between stromal CD10 status and other markers (ER, PR and Her-2/neu). These discrepancies in the results can be due to following limitations.

\section{Limitations}

- $\quad$ Sample size was less probably due to the COVID -19 pandemic.

- $\quad$ Equivocal Her-2/neu scores i.e 2+ were not further evaluated by FISH. 


\section{References}

1. Ganesh N. Sharma, Rahul Dave and K. K Sharma Cancer-Its various types along with causes, symptoms, treatments and stages, in: cancer info guide. 2009.

2. Ghoncheh M, Momenimovahed Z, Salehiniya H. Epidemiology, Incidence and Mortality of Breast Cancer in Asia. Asian Pac J Cancer Prev. 2016;17(S3):4752. doi: 10.7314/apjcp.2016.17. s3.47. PMID: 27165207.

3. GLOBOCAN 2020, INTERNATION JOURNAL OF CANCER; November 2020.

4. Hala N Hosni, M. D. Ahmed, ABD EL Aziz,M. D. ; Sahara A. Tabak,M. D and Maha Elsayed; Immunohistochemical study of stromal CD10 expression in Mammary duct carcinoma. Med J. Cairo Univ, 2012; 80,No 2:37-44.

5. S. Premalatha;Analysis of CD10 Expression in Breast Carcinoma in Post Menopausal Patients. "IOSR Journal of Dental and Medical Sciences(IOSrJDMS)16.7(2017);71-74.

6. Jana SH, Jha BM, Patel C, Jana D, Agarwal A. CD10-A new prognostic stromal marker in breast carcinoma, its utility, limitations and role in breast cancer pathogenesis. Indian $\mathrm{J}$ Pathol Microbiol 2014;57:530-6.

7. John S Meyer, Consuelo Alvarez, Clara Milikowski, Neal Olson,Irma Russo, Jose Russo,Andrew Glass, A Zehnbauer, Karen Lister, Reza Parwaresch. Breast carcinoma malignancy grading by Bloom Richardson system vs proliferation index: reproducibility of grade and advantages of proliferation index. Moderen Pathology 2005;18:1067-1078.

8. Louhichi T., Saad, H. , Dhiab, M. B. et al. Stromal CD10 expression in breast cancer correlates with tumor invasion and cancer stem cell phenotype. BMC Cancer 18, 49 (2018). https://doi. org/10.1186/s12885-
017-3951-8

9. Kaur M, Kaur H, Manjari M, Vikrant Rai, Kiranjot Kaur. Assessment of clinical parameters and histopathological grading of breast cancer. International Journal of Contemporary Medical Research 2016;3 (10);2938-2941.

10. Moritani S, Kushima R, Sugihara H, Bamba M, Kobayashi TK, Hattori T Mod Pathol. (2002) Apr;15(4):397-405.

11. Breasted JH, editor. The Edwin Smith Surgical papyrus. Chicago, Illinois: The University Chicago Press; 1930. special edition, 1984

12. Grossing of Surgical Oncology Specimens. Department of Pathology, Tata Memorial Hospital.2011:56-69.

13. B. V Anuradha Devi, S. Chandra Sekhar, C. Saritha, S. Sanhya Anil, H. Sandhya Rani. A study on stromal CD10 expression in invasive breast carcinoma. IAIM, 2016;3(6):142-147.

14. Block GE, Jensen EV, Polley TZ. The prediction of hormonal dependency of mammary cancer. Ann Surg. 1978; 182:342-52.

15. Hutchinson WB, Thomas DB, Hamlin WB, et al. Risk of breast cancer in women with benign breast disease. J Natl Cancer Inst 1980;65:13-20.

16. Taghizadeh-Kermani A, Jafarian AH, Ashabyamin R, Seilanian-Toosi M, Pourali L,Asadi M, Mashhadi L. The Stromal Overexpression of CD10 in Invasive Breast Cancer and its Association with Clinicopathologi Factors. Iran J Cancer Prev.2014;7(1):17-21.

17. Alla H Raziq, Sarah M Masoud. The correlation of stromal $\mathrm{Cd} 10$ expression in invasive breast cancer with various clinicopathological parameters. Iraqi $\mathrm{J}$. Comm. Med 2017;3:129-135.

18. Puri V, Jain Manjula \& Thomas, Shaji. (2011). Stromal Expression of CD10 in Invasive Breast Carcinoma and Its 
Correlation with ER, PR, HER2-neu, and Ki67. International journal of breast cancer. 2011.

19. Mohammadizadeh F, Salavati M, Afshar Moghaddam N. CD10 expression in stromal component of invasive breast carcinoma: A potential prognostic determinant. J Res Med Sci 2012; 17(Spec 2):S 194-9. 